\title{
Enhancing Patient Activation and Self-Management Activities in Patients With Type 2 Diabetes Using the US Department of Defense Mobile Health Care Environment: Feasibility Study
}

Ronald W Gimbel ${ }^{1}$, PhD; Lior M Rennert ${ }^{1}$, PhD; Paul Crawford ${ }^{2}$, MD; Jeanette R Little ${ }^{3}$, MS; Khoa Truong ${ }^{1}$, MA, $\mathrm{PhD}$; Joel E Williams ${ }^{1}$, MPH, PhD; Sarah F Griffin ${ }^{1}$, MPH, PhD; Lu Shi ${ }^{1}$, PhD; Liwei Chen ${ }^{4}$, MD, PhD; LingLing Zhang $^{5}$, ScD; Jennie B Moss ${ }^{2}$, BSN, MS; Robert C Marshall ${ }^{6}$, MPH, MD; Karen W Edwards ${ }^{1}$, MS; Kristy J Crawford ${ }^{2}$, BSN; Marie Hing ${ }^{7}$, MS; Amanda Schmeltz ${ }^{3}$, MEd; Brandon Lumsden ${ }^{1}$, MS; Morgan Ashby ${ }^{1}$, MS; Elizabeth Haas ${ }^{1}$, BS; Kelly Palazzo ${ }^{1}$, BS

\footnotetext{
${ }^{1}$ Department of Public Health Sciences, Clemson University, Clemson, SC, United States

${ }^{2}$ Nellis Family Medicine Residency Program, Mike O'Callaghan Federal Hospital, Las Vegas, NV, United States

${ }^{3}$ Mobile Health Innovation Center, Telemedicine \& Advanced Technologies Research Center, U.S. Army Medical Research \& Materials Command, Fort Gordon, GA, United States

${ }^{4}$ Fielding School of Public Health, University of California Los Angeles, Los Angeles, CA, United States

${ }^{5}$ College of Nursing and Health Sciences, University of Massachusetts Boston, Boston, MA, United States

${ }^{6}$ Clinical Informatics Fellowship Program, Madigan Army Medical Center, Tacoma, WA, United States

${ }^{7}$ Department of Internal Medicine, Madigan Army Medical Center, Tacoma, WA, United States
}

\section{Corresponding Author:}

Ronald W Gimbel, $\mathrm{PhD}$

Department of Public Health Sciences

Clemson University

501 Edwards Hall

Clemson, SC, 29634

United States

Phone: 15405223759

Email: rgimbel@clemson.edu

\section{Abstract}

Background: Past mobile health (mHealth) efforts to empower type 2 diabetes (T2D) self-management include portals, text messaging, collection of biometric data, electronic coaching, email, and collection of lifestyle information.

Objective: The primary objective was to enhance patient activation and self-management of T2D using the US Department of Defense's Mobile Health Care Environment (MHCE) in a patient-centered medical home setting.

Methods: A multisite study, including a user-centered design and a controlled trial, was conducted within the US Military Health System. Phase I assessed preferences regarding the enhancement of the enabling technology. Phase II was a single-blinded 12-month feasibility study that randomly assigned 240 patients to either the intervention $(n=123$, received mHealth technology and behavioral messages tailored to Patient Activation Measure [PAM] level at baseline) or the control group ( $\mathrm{n}=117$, received equipment but not messaging. The primary outcome measure was PAM scores. Secondary outcome measures included Summary of Diabetes Self-Care Activities (SDSCA) scores and cardiometabolic outcomes. We used generalized estimating equations to estimate changes in outcomes.

Results: The final sample consisted of 229 patients. Participants were $61.6 \%(141 / 229)$ male, had a mean age of 62.9 years, mean glycated hemoglobin $\left(\mathrm{HbA}_{1 \mathrm{c}}\right)$ of $7.5 \%$, mean BMI of 32.7, and a mean duration of T2D diagnosis of 9.8 years. At month 12 , the control group showed significantly greater improvements compared with the intervention group in PAM scores (control mean 7.49, intervention mean 1.77; $P=.007$ ), $\mathrm{HbA}_{1 \mathrm{c}}$ (control mean -0.53 , intervention mean $-0.11 ; P=.006$ ), and low-density lipoprotein cholesterol (control mean -7.14, intervention mean 4.38; $P=.01$ ). Both groups showed significant improvement in SDSCA, BMI, waist size, and diastolic blood pressure; between-group differences were not statistically significant. Except for patients with the highest level of activation (PAM level 4), intervention group patients exhibited significant improvements in 
PAM scores. For patients with the lowest level of activation (PAM level 1), the intervention group showed significantly greater improvement compared with the control group in $\mathrm{HbA}_{1 \mathrm{c}}$ (control mean -0.09 , intervention mean $-0.52 ; P=.04$ ), BMI (control mean 0.58 , intervention mean $-1.22 ; P=.01$ ), and high-density lipoprotein cholesterol levels (control mean -4.86 , intervention mean 3.56; $P<.001)$. Significant improvements were seen in AM scores, SDSCA, and waist size for both groups and in diastolic and systolic blood pressure for the control group; the between-group differences were not statistically significant. The percentage of participants who were engaged with MHCE for $\geq 50 \%$ of days period was $60.7 \%$ (68/112; months $0-3), 57.4 \%$ (62/108; months 3-6), 49.5\% (51/103; months 6-9), and 43\% (42/98; months 9-12).

Conclusions: Our study produced mixed results with improvement in PAM scores and outcomes in both the intervention and control groups. Structural design issues may have hampered the influence of tailored behavioral messaging within the intervention group.

Trial Registration: ClinicalTrials.gov NCT02949037; https://clinicaltrials.gov/ct2/show/NCT02949037

International Registered Report Identifier (IRRID): RR2-10.2196/resprot.6993

(J Med Internet Res 2020;22(5):e17968) doi: $\underline{\text { 10.2196/17968 }}$

\section{KEYWORDS}

mHealth; diabetes mellitus; patient activation; patient-centered care; eHealth

\section{Introduction}

\section{Background}

Type 2 diabetes (T2D) is a chronic disease with high rates of disability, impaired quality of life, and premature death [1-6]. The prevalence of $\mathrm{T} 2 \mathrm{D}$ is increasing at an alarming rate in the United States; in 2017, the estimated number of patients was 30.3 million or about $9.4 \%$ of the adult population [2,3,7]. T2D is the leading cause of blindness, nontraumatic amputations, and adult renal failure [8], and it reduces life expectancy by 5 to 10 years [2]. On average, the medical expenditure of patients with T2D is about 2.3 times greater than that of a T2D-free individual [9]. The potential for mobile health (mHealth) technologies in the care of patients with T2D and other chronic conditions to date have assessed a variety of tools and techniques. Some of the most promising tools and techniques include regular collection of biometric devices (eg, glucometers, activity monitors [10,11], SMS messaging [10,12-16], secure email communication with clinical teams, and regular reporting of quality-of-life variables [17-20]). Each of these tools, used alone or in combination, has demonstrated varying degrees of effectiveness. In this study, we sought to incorporate several of the most promising mHealth capabilities in a patient-centered medical home (PCMH) workflow.

The concept of patient activation, detailed in our protocol [21], has been demonstrated to correlate with improved clinical outcomes, increased preventative care, and overall lower health care-related cost [22-25]. Research on increased activation and improved clinical outcomes using patient portal and personal health record (PHR)-based interventions have provided mixed results [16,26-33]. It is noteworthy that early manuscripts did not provide substantial detail related to the design and navigation of portal or PHRs or whether the embedded intervention included behavioral reinforcement. Several studies have demonstrated a relationship between increased patient activation and improved clinical outcomes (eg, hypertension, smoking, BMI, and glycated hemoglobin [ $\left.\mathrm{HbA}_{1 \mathrm{c}}\right]$ ) [5,16,25,34-38], whereas other studies did not achieve significant improvement in clinical outcomes $[5,37,39]$. There is evidence to suggest that activated patients are more likely to practice healthy behaviors related to their diet $[37,40]$ and physical activity $[37,41]$, better manage their T2D [37], and obtain preventive screenings [42].

\section{Objective}

The primary goal of this research was to enhance patient activation and improve self-management of T2D using the US Department of Defense's (DoD) Mobile Health Care Environment (MHCE) in a PCMH setting. We hypothesized that the MHCE intervention will lead to improvement in patient activation, increase in T2D self-care, and improvement in clinical outcomes.

\section{Methods}

\section{Trial Design}

The trial design and methods are described in detail elsewhere [21]. This was a feasibility study within the DoD's Military Health System, which included a user-centered design phase and a feasibility trial conducted at two sites. In phase I, we assessed both patient and clinician preferences regarding MHCE technology capabilities and enhancements for T2D care. The phase II research was a single-blinded (patients only) 12-month feasibility study that incorporated randomization principles. We employed a 1:1 allocation ratio between the intervention and control groups.

The study was approved by the Institutional Review Boards (IRB) of Clemson University (\#IRB2015-234) and the Madigan Army Medical Center (IRB \#216073). The study was registered with ClinicalTrials.gov (NCT02949037) on October 31, 2016.

\section{Participant Enrollment}

Patients were recruited from the PCMH clinic schedule, provider referrals, distributed posters and fliers, and population health databases. Potential participants were scheduled for a screening visit with a study staff member to establish eligibility, discuss and execute an informed consent document, and were administered the Patient Activation Measure (PAM) instrument. Patients' PAM levels placed them in a stratified group, where 
patients were randomly allocated to intervention or control groups.

Clinicians practicing in the respective PCMH sites were invited to participate by the site's principal investigator; this was a convenience sample. The clinician participants met with their senior research associate to review the IRB-approved minimal-risk information sheet. For phase II, clinicians signed an informed consent document. The clinician participants were not blinded to the study.

\section{Inclusion and Exclusion Criteria}

Inclusion criteria for patient participation in phase I or II research included men and women (1) aged 18 years or older, (2) with the ability to understand and read English, (3) enrolled for primary care at one of the target PCMH sites, and (4) with a diagnosis of T2D. In addition, in phase II, we sought to recruit a maximum of 120 participants (per PCMH), with a proportional distribution of patients with PAM levels 1 through 4; a primer on PAM levels is included elsewhere [21,43]. As this is a feasibility study, we did not derive the 120 per site recruitment numbers from power calculations.

Inclusion criteria for clinician participation in phase I or II research included (1) physicians, physician assistants, nurse practitioners, or nurses at the target PCMHs and (2) providing care for patients with T2D.

Exclusion criteria for patient participation in phase I or II research included the following: (1) pregnant women; (2) non-English-speaking patients; (3) patients receiving hospice care; (4) patients having active cancer and receiving treatment with chemotherapy or radiation therapy; (5) patients taking warfarin; (6) patients that have been a recipient of gastric bypass or a similar procedure; (7) patients having a diagnosis of uncontrolled hypothyroidism; (8) patients having known Cushing syndrome; (9) patients being treated with oral steroids; (10) patients with known liver disease; (11) patients with a current diagnosis of cognitive impairments that would interfere with the use of technology; (12) patients having congestive heart failure, in New York Heart Association functional classification III or IV; and (13) patients unable to use a mobile device due to cognitive or physical impairments during initial screening.

Exclusion criteria for clinician participation in phase I or II research included the following: (1) not affiliated with the target site and (2) not providing care for patients with T2D.

\section{Setting and Site Selection}

We sought to purposefully assess MHCE use in T2D care in two distinctly different PCMH environments and locations. The patient base included those on active duty, retirees, and dependents who have typically spent years in the military.

The Madigan Army Medical Center was the US Army's second largest military treatment facility located in Tacoma, Washington, and was a tertiary facility with a level II trauma center and robust graduate medical education programs. They served a patient base of approximately 118,000 patients; about 7500 (or $>6 \%$ ) were living with T2D. Of the T2D population, about $15.00 \%(1125 / 7500)$ were active duty members or their dependents, and about $85.00 \%$ (6375/7500) were retirees and their dependents. Over half of the patients with T2D were aged 57-76 years. The study location within the medical center was an Internal Medicine PCMH with approximately 14,300 enrolled patients supported by a staff of 77 including 12 staff physicians and 8 residents.

The Mike O'Callaghan Federal Medical Center was a federal facility in the greater Las Vegas, Nevada area, which served approximately 47,000 patients; about 4500 (>9\%) were living with T2D. Of the T2D population, about $4.00 \%$ (180/4500) were active duty members or their dependents, and about $96.00 \%$ (4320/4500) were retirees and their dependents. Over $72.00 \%(3240 / 4500)$ of the patients with T2D were aged $\geq 60$ years. The study location within the medical center was a Family Medicine PCMH with approximately 7500 enrolled patients supported by a staff of 62 including 9 staff physicians and 26 residents.

\section{Description of the Mobile Health Care Environment}

The DoD's MHCE system is a secure health information system designed to support health services delivery and mHealth. The MHCE meets all physical and information security mandates, as prescribed by federal law and DoD regulation, for the protection of personal health information and personally identifiable information.

\section{Intervention Overview}

The intervention has been described elsewhere [21]. This intervention enhanced MHCE in several ways. First, the intervention enhanced the capacity to include collection and visualization of data from Bluetooth-enabled medical devices. This included mapping data from device output into the MHCE, developing data visualization appropriate for mHealth and clinical care (eg, graphing outcomes and temporal trend patterns), migrating data to an analysis cell, and developing decision-support algorithms that drive safety alerts and behavioral message reinforcement. The devices used in this study included a Bluetooth-enabled scale, glucometer, blood pressure reader, and activity monitor. Second, the intervention expanded the capacity of the MHCE analysis cell to manage large amounts of data and to conduct both routine reports and research applications. Third, the intervention added patient activation and associated measurement instruments to capture baseline and ongoing changes to patient activation. Fourth, the intervention expanded the MHCE messaging platform that research associates used to send tailored behavioral messaging to patients in an effort to influence greater activation and reinforce positive behavior. An annotated visual presentation of patient screenshots and workflow is included in Multimedia Appendix 1.

The MHCE was accessed by mobile phones and tablets that used either an IOS or Android platform. The MHCE requires internet access for patients to sync data from devices to the MHCE backend portal, to receive tailored behavioral messages, or to support other functions accessible by clinicians (Multimedia Appendix 2). During the study, patients received SMS messages with hyperlinks to a separate secure information system platform used for the administration and analysis of 
PAM and Summary of Diabetes Self-Care Activities (SDSCA) instruments.

\section{Tailored Behavioral Messaging}

A primary component of the MHCE system was tailored behavioral messaging. In this study, the research team developed behavioral messages tailored for each of the four PAM score levels; in total, we developed over 360 messages. The messages fell within 9 functional areas common to T2D care and the SDSCA survey: nutrition, home monitoring, physical activity, blood pressure, foot care, medications, smoking, glucose control, and general behavioral reinforcement. The message development process is outlined below (Textbox 1).

Textbox 1. Tailored behavioral messaging development process.

A multistage message development process was guided by patient activation levels and theoretical constructs relevant to those levels. Specifically:

- Step 1: Health behavior researchers developed messages tailored for each of the four Patient Activation Measure (PAM) score levels and five type 2 diabetes self-care behaviors measured by the Summary of Diabetes Self-Care Activities.

- $\quad$ Step 2: Messages were assessed by two-person teams for content accuracy, reading level, and message appropriateness for the PAM level. Messages were then revised based on this review process. A clinical advisory team consisting of clinicians and researchers reviewed and approved the messages for clinical relevance and content.

- Step 3: A pretest $(\mathrm{n}=21)$ of the messages with a population similar to those targeted for the larger study was administered. Each person was provided with a random sample of five messages based on their PAM level. They were then asked four close-ended questions and one open-ended question about the messages.

- Step 4: Researchers reviewed PAM level-specific messages and rated them as acceptable, questionable, or unacceptable based on appropriateness for PAM level, behavioral theory construct, reading level, and content accuracy. Messages were then revised based on this review process.

This process supported triangulation review of findings that yielded a set of 360 PAM-level appropriate messages. At each step in the process, messages were reviewed and revised based on research team member feedback (stages 2 and 4) or by potential study participant feedback (stage 3). Overall, the first two steps in the process produced messages with a high degree of acceptability by people very similar to the study population. Pretest participants found the messages to be encouraging, useful, applicable, and impactful. This indicates a high level of credibility with regard to the application of the theoretical constructs within the messages.

For patients with baseline PAM level 1, we used messages addressing the emotional state of feeling overwhelmed and passive with an emphasis on the importance of taking action. PAM level 2 messages were designed to build knowledge and self-efficacy and focus on taking small steps that can be accomplished without much in-depth knowledge. PAM level 3 messages focused on building self-management skills, such as goal setting and self-monitoring. PAM level 4 messages focused on avoiding relapse when stressed.

In phase II of our study, tailored behavioral messages were delivered to each intervention group participant, via the MHCE accessed through their mobile device, based on both senior research associate-initiated and algorithm-automated schedules and thresholds developed according to PAM level, SDSCA responses, and agreed-upon general rotation. Senior research associates used the MHCE backend portal control panel for manual rotational scheduling of messages delivered 3 days per week. Participant responses to the SDSCA and data from synced devices triggered additional messaging if their clinical readings from biomedical devices exceeded the established thresholds. If a patient's PAM level changed within the course of the study, the tailored behavioral messaging to that patient changed to align with the new PAM level.

\section{Phase I User-Centered Design}

In phase I, we captured feedback from patients on MHCE navigation, use of external devices, ease of use, and satisfaction. We collected baseline research participant data following informed consent. One researcher led individual participants through usability testing, and an additional researcher-observer recorded observations using an observation guide for recording time on task, number of attempts by task, task sequences, and participant questions/comments. Following a researcher-provided demonstration of the MHCE, each participant was requested to concurrently navigate each component of the MHCE system via a mini tablet device under their control. For each task, each participant was asked three open-ended questions to evaluate task-specific user satisfaction. The researcher delivered a brief demonstration of the external devices used in the study. Participants were requested to (1) manually upload data, (2) sync each device with the app, and (3) interpret graphs. The data collection instrument used in phase I is shown in Multimedia Appendix 3.

Researchers have evaluated usability by applying definitions and evaluation metrics guided by the International Organization for Standardization's 9241-11 usability framework and mHealth usability research [44]. Specific metrics to evaluate usability are effectiveness, efficiency, and satisfaction. Researchers used the Single Ease Question to evaluate informant satisfaction immediately after performing each task [45]. The system usability scale (SUS) was measured for overall informant satisfaction with the MHCE [46].

We assessed clinician preferences in phase I using focus groups at each study site. Two trained researchers facilitated focus groups using a semistructured interview guide to elicit feedback about the MHCE (Multimedia Appendix 4). A four-member team completed a thematically organized data analysis of the clinician and nurse feedback using an inductive narrative approach [47-49]. 


\section{Phase II Controlled Study: Patient Enrollment and Study Flow}

In phase II, we aimed to recruit 240 patients (120 per site), with one half assigned to a control group. Eligible patients were assigned to four strata according to their PAM levels. After all patients were assigned, simple randomization was performed within each stratum to assign patients to either the MHCE (intervention) or control groups. Phase II research was conducted between July 2017 and November 2018.

\section{Mobile Health Care Environment Intervention Versus Intervention-Lite (Control)}

Patients in both the intervention and intervention-lite (control) groups received the device package mentioned above. These devices collected and recorded biometric data; participants were trained on the biomedical device and peripheral equipment use.

For the intervention group, the devices were mapped to the MHCE system accessible from the patients' mobile phone or an iPad mini tablet device. Data from their biomedical devices were visually presented in the MHCE with trend and scalable options. Safety algorithms were mapped to these clinical data to alert the participant and, depending on the measure, the clinical team when readings exceeded the established thresholds. The devices for the control group participants were not connected to the MHCE system.

\section{Initial Outcome Measures for Patient Component}

Primary outcome measures included the PAM scores. Secondary outcome measures in the study were (1) SDSCA responses, (2) clinical measures (Textbox 1), (3) comorbid conditions, and (4) SUS survey scores.

\section{Patient Activation Measure Instrument}

The self-reported PAM survey is associated with self-management behaviors, medication adherence, patient satisfaction, and quality of life [50,51]. Within a T2D-specific population, PAM is not related to knowledge regarding $\mathrm{HbA}_{1 \mathrm{c}}$ (the standard measure of average blood glucose level [52]), but it is associated with better glycemic control [53]. The PAM is a valid, reliable, unidimensional, and probabilistic Guttman-like scale instrument [43], and it is a standard tool to measure patient activation. We administered the PAM at screening visits in phases I and II and electronically every 3 months during phase II for both the intervention and control groups. In computing PAM in the analysis, we leveraged the 0-100 scoring mechanism based on licensing guidance from Insignia Health. PAM levels 1-4 are determined by the continuous PAM score.

\section{Summary of the Diabetes Self-Care Activities Instrument}

The SDSCA instrument is a brief self-report instrument for measuring levels of self-management across different components of the T2D regimen [54]. The SDSCA includes 11 core items associated with T2D self-care. The SDSCA has been successfully used in numerous T2D studies both within and outside the United States [54-58]. The SDSCA has been validated and is considered a standard instrument in T2D care for measuring self-care activities [54]. We administered the SDSCA at the intake visit for phase II and electronically every 2 weeks during phase II for both the intervention and control groups.

\section{Clinical Measures}

We collected clinical measures (Textbox 2) from patients at intake during phase I research. We collected and compared changes in clinical measures for both groups in phase II at 3 points: intake, midpoint (month six), and conclusion (month 12). Data were manually abstracted by senior research associates from the PHR. For patients assigned to the MHCE intervention group, the MHCE system recorded weight, systolic blood pressure, diastolic blood pressure, and blood glucose values to the MHCE module on a regular basis via Wi-Fi or Bluetooth-enabled peripheral equipment.

Textbox 2. Clinical measures in phase II.

- $\quad$ Glycated hemoglobin

- Low-density lipoprotein

- High-density lipoprotein

- $\quad$ BMI

- Abdominal circumference

- Systolic blood pressure

- Diastolic blood pressure

\section{System Usability Scale Survey}

The SUS survey is a 10-item Likert-like scaled survey used to convey a subjective assessment of system usability. The instrument was developed over 15 years ago and is used to measure the usability of websites [59]. In this study, we substituted the term "MHCE system" for the term "website" in the instrument. Phase I participants completed the SUS survey at the conclusion of the encounter. Phase II intervention group participants completed the SUS survey at the midpoint and study conclusion.

\section{Comorbid Conditions}

We assessed and documented comorbid conditions among both the control and intervention groups during the prescreening of eligibility, at intake, at study midpoint, and at study conclusion. Although not primary outcome measures, any change in comorbid conditions was assessed. 


\section{Data Analysis Strategy}

We conducted the primary analyses for phase II using an intent-to-treat approach. Achievement of randomization was evaluated by comparing the baseline key variables between the MHCE intervention group and the control group. These baseline characteristics were compared using Kruskal-Wallis tests for continuous variables, Cochran-Armitage trend tests for ordinal variables, and chi-squared tests for binary variables and multinomial variables. Exact tests were performed to account for categorical variables with small cell counts.

Generalized estimating equations (GEE) with an autoregressive correlation structure were used to test the hypotheses that patients who participated in MHCE had higher PAM, SDSCA, and improved selected clinical outcomes and comorbid conditions than their control counterparts. The predictors in the model included a binary variable for a group, a three- or five-level categorical variable for time (depending on the number of repeated measurements for the outcome), and their interaction. All models included covariate adjustment for site, age, sex, race, duration of disease, work status, and baseline physical activity level. As the intervention group messages were tailored to each subject based on their baseline PAM level, we examined the effect of intervention within each baseline PAM level by including a three-way interaction between intervention, time, and baseline PAM level in the GEE models. CIs are reported to assess changes within groups. Within-group changes (from baseline) in outcomes are deemed significant at the alpha $=.05$ level if the estimated CIs exclude 0. Between-group comparisons of change (from baseline) in outcomes are deemed significant for two-sided $P$ values $<0.5$.

GEE were also used to test the hypothesis that patients who engaged at a higher rate with the interactive and tailored mobile technology in MHCE realized greater improvement in PAM level, SDSCA, and clinical measures. We defined the main independent variable for MHCE usage by an indicator variable set to 1 if the percentage of days engaged with MHCE in a 3-month period exceeded $80 \%$ (strong adherence). As adherence varies with time, the GEE model assumed working independence for the correlation structure [60]. All GEE analyses were conducted using the Generalized Linear Model procedure in the Statistical Analysis System.

\section{Results}

\section{Phase I-User-Centered Design Research Participants}

The research team recruited 10 research participants per site, with 20 participants for phase I. The study sample was $70 \%$ $(14 / 20)$ male, 65\% (13/20) white, middle-aged (average 62.8, range 40-82 years), obese (median BMI 33.7, range 24.3-43.5), with elevated blood sugar levels (median $\mathrm{HbA}_{1 \mathrm{c}}$ 7.2, range 5.8-12.2), and increased patient activation, 75\% (15/20) with PAM level 3 scores at intake. Phase I research was conducted between November and December 2016.

\section{Phase I-Participant (Patients) Effectiveness With Mobile Health Care Environment Technology}

Overall, participants performed better with goal-setting tasks (almost all completed these tasks without assistance), showed some difficulty with tasks that required manual entry (the majority could do so with little to no assistance), and had the most difficulty with Bluetooth syncing of devices (approximately half needed assistance or could not complete; Table 1).

Table 1. Phase I participant effectiveness with the technology. Here, $\mathrm{n}$ denotes the number of responses in each category.

\begin{tabular}{|c|c|c|c|c|c|c|c|c|c|}
\hline Site and effectiveness & $\begin{array}{l}\text { Blood pres- } \\
\text { sure goal set- } \\
\text { ting }\end{array}$ & $\begin{array}{l}\text { Glucose } \\
\text { goal setting }\end{array}$ & $\begin{array}{l}\text { Weight } \\
\text { goal set- } \\
\text { ting }\end{array}$ & $\begin{array}{l}\text { Steps } \\
\text { goal set- } \\
\text { ting }\end{array}$ & $\begin{array}{l}\text { BP manu- } \\
\text { al entry }\end{array}$ & $\begin{array}{l}\text { BP sync } \\
\text { with de- } \\
\text { vice }\end{array}$ & $\begin{array}{l}\text { Glucose } \\
\text { manual en- } \\
\text { try }\end{array}$ & $\begin{array}{l}\text { Weight } \\
\text { manual } \\
\text { entry }\end{array}$ & $\begin{array}{l}\text { Weight } \\
\text { sync with } \\
\text { device }\end{array}$ \\
\hline \multicolumn{10}{|l|}{ Madigan, $\mathbf{n}$} \\
\hline Completed without help & 9 & 9 & 9 & 5 & 7 & 1 & 7 & 5 & 4 \\
\hline Needed hints & 1 & 0 & 1 & 4 & 3 & 7 & 3 & 5 & 3 \\
\hline Failed to complete & 0 & 1 & 0 & 1 & 0 & 2 & 0 & 0 & 3 \\
\hline \multicolumn{10}{|l|}{ Nellis, $\mathbf{n}$} \\
\hline Completed without help & 8 & 9 & 8 & 9 & 8 & 4 & 9 & 7 & 6 \\
\hline Needed hint(s) & 2 & 1 & 2 & 1 & 2 & 6 & 1 & 3 & 4 \\
\hline Failed to complete & 0 & 0 & 0 & 0 & 0 & 0 & 0 & 0 & 0 \\
\hline \multicolumn{10}{|l|}{ Combined, $\mathbf{n}$} \\
\hline Completed without help & 17 & 18 & 17 & 14 & 15 & 5 & 16 & 12 & 10 \\
\hline Needed hint(s) & 3 & 1 & 3 & 5 & 5 & 13 & 4 & 8 & 7 \\
\hline Failed to complete & 0 & 1 & 0 & 1 & 0 & 2 & 0 & 0 & 3 \\
\hline
\end{tabular}


Phase I-Participant (Patient) Efficiency With Mobile Health Care Environment Technology

Overall, goal setting and manual entry tasks took the least amount of time to complete, and Bluetooth syncing tasks took the most time (Table 2).

\section{Phase I-Participants and System Usability Survey Results}

All phase I participants were administered a SUS related to MHCE use. The survey results were very favorable and related to the usability of MHCE. Specifically:

- $\quad$ SUS overall, Mean (SD): 83.8 (SD 14.9)=A+

- Usability sub factor, mean (SD): 86 (SD 13.4)=A+

- Learnability subfactor, mean (SD): 75 (SD 27.5)=A-

\section{Phase I-Results of the Qualitative Research Component (Patient Participants)}

All participating participants indicated that the MHCE would "help them manage their diabetes" and give their health care provider a "better report of their health." As expected, patients rated navigation tasks as "less difficult" and peripheral device tasks, for example, syncing, as "more difficult." An overview of usability testing and patient feedback is included in Multimedia Appendix 5. Participants committed fewer errors with basic navigation tasks and more with peripheral devices. Patient participants suggested minor changes regarding the look and function of the app (Textbox 3).

\section{Phase I-Results of the Qualitative Research Component (Clinicians)}

Overall, clinicians voiced a sense of optimism for the MHCE system, tempered with recommendations aimed at improving the patient experience, clinician adoption, and use of the data it generated. Clinician participants also suggested changes related to quality and safety (Textbox 4).

\section{Technology Adaptation Following Phase I Research and Before the Launch of Phase II}

Patient and clinician suggestions were reviewed and incorporated as adaptations by our technology team within system constraints. A total of 29 specific recommendations were made to the technology team; $86 \% \quad(25 / 29)$ of the recommendations were positively acted on and modifications occurred. Only 4 recommendations could not be supported (Textbox 5).

Table 2. Participant efficiency with technology.

\begin{tabular}{|c|c|c|c|c|c|c|c|c|c|}
\hline Task & $\begin{array}{l}\mathrm{BP}^{\mathrm{a}} \text { goal } \\
\text { setting }\end{array}$ & $\begin{array}{l}\text { Glucose } \\
\text { goal setting }\end{array}$ & $\begin{array}{l}\text { Weight goal } \\
\text { setting }\end{array}$ & $\begin{array}{l}\text { Steps goal } \\
\text { setting }\end{array}$ & $\begin{array}{l}\text { BP manual } \\
\text { entry }\end{array}$ & $\begin{array}{l}\text { BP sync } \\
\text { with device }\end{array}$ & $\begin{array}{l}\text { Glucose } \\
\text { manual entry }\end{array}$ & $\begin{array}{l}\text { Weight man- } \\
\text { ual entry }\end{array}$ & $\begin{array}{l}\text { Weight sync } \\
\text { with device }\end{array}$ \\
\hline $\begin{array}{l}\text { Madigan, } \\
\text { mean }^{b}(\mathrm{SD})\end{array}$ & $\begin{array}{l}55.02 \\
(37.08)\end{array}$ & $\begin{array}{l}19.83 \\
(7.80)\end{array}$ & $\begin{array}{l}40.18 \\
(45.57)\end{array}$ & $\begin{array}{l}61.31 \\
(54.80)\end{array}$ & $\begin{array}{l}48.00 \\
(31.01)\end{array}$ & $\begin{array}{l}121.74 \\
(28.09)\end{array}$ & $\begin{array}{l}32.09 \\
(15.96)\end{array}$ & $\begin{array}{l}54.09 \\
(38.54)\end{array}$ & $\begin{array}{l}65.08 \\
(27.18)\end{array}$ \\
\hline $\begin{array}{l}\text { Nellis, mean } \\
\text { (SD) }\end{array}$ & $\begin{array}{l}51.53 \\
(53.12)\end{array}$ & $\begin{array}{l}30.29 \\
(18.77)\end{array}$ & $\begin{array}{l}19.02 \\
(12.67)\end{array}$ & $\begin{array}{l}19.91 \\
(11.75)\end{array}$ & $\begin{array}{l}46.44 \\
(32.56)\end{array}$ & $\begin{array}{l}103.04 \\
(47.05)\end{array}$ & $\begin{array}{l}30.10 \\
(20.95)\end{array}$ & $\begin{array}{l}35.37 \\
(23.98)\end{array}$ & $\begin{array}{l}68.09 \\
(37.23)\end{array}$ \\
\hline $\begin{array}{l}\text { Combined sites, } \\
\text { mean (SD) }\end{array}$ & $\begin{array}{l}53.18 \\
(45.00)\end{array}$ & $\begin{array}{l}25.64 \\
(15.50)\end{array}$ & $\begin{array}{l}29.60 \\
(34.31)\end{array}$ & $\begin{array}{l}40.61 \\
(44.04)\end{array}$ & $\begin{array}{l}47.22 \\
(30.97)\end{array}$ & $\begin{array}{l}111.90 \\
(39.37)\end{array}$ & $\begin{array}{l}31.09 \\
(18.15)\end{array}$ & $\begin{array}{l}44.73 \\
(32.69)\end{array}$ & $\begin{array}{l}66.75 \\
(32.25)\end{array}$ \\
\hline
\end{tabular}

${ }^{\mathrm{a}} \mathrm{BP}$ : blood pressure.

${ }^{b}$ Mean denotes mean time in seconds.

Textbox 3. Participants' suggestions for Mobile Health Care Environment improvement.

- Suggestion \#1: To increase the size of icons as they were difficult to see.

- Suggestion \#2: To improve glucose graph responsiveness.

- Suggestion \#3: To increase the font size for the Mobile Health Care Environment (MHCE) interface.

- Suggestion \#4: To allow past dates for manual entry into the MHCE.

Textbox 4. Clinicians' suggestions related to app safety alert functions.

- Change default blood glucose entry to "Unclassified," forcing patient entry of "after meal," "bedtime," or "fasting."

- Define "after meal" glucose as $>120$ min post meal.

- Simplify safety alerts on the backend clinician portal.

- Add icons besides safety alerts.

- Add patient target ranges on graphs. 
Textbox 5. Recommendations that could not be adopted.

\footnotetext{
1. Desire for additional colors (limited colors were available).

2. Remove signal and refresh buttons (component of the base system).

3. Add alert icons (limited icon choices available).

4. Automatic syncing of devices (system could not support)
}

\section{Safety Algorithms Developed and Deployed in Phase II}

The research team developed and implemented a series of safety alerts into the MHCE technology. These include thresholds and alerts for high/low blood glucose, high/low blood pressure, and weight loss/gain. Details on safety alerts are identified in a report attached as Multimedia Appendix 6.

\section{Phase II-Participant Randomization, Retention, and Comorbidities}

A total of 240 participants met the study eligibility criteria and were randomized (117 to control group and 123 to intervention group). Of the 117 participants randomized to the control group, 5 withdrew before intake, 3 declined participation, and 2 did not meet the inclusion/exclusion criteria. Of the 123 participants randomized to the intervention group, 6 withdrew before intake, 3 declined participation, 1 did not meet the inclusion/exclusion criteria, and 2 did not provide reason. Thus, the final sample size consisted of 229 participants, with 112 randomized to the control group and 117 randomized to the intervention group.

Study retention and participation was high; 93.0\% (213/229) of participants remained in the study through 12 months: $99.1 \%$ $(111 / 112)$ in the control group and $86.3 \%(101 / 117)$ in the intervention group. One participant who withdrew from the control group cited a lack of ability to use the physical activity monitor as their primary reason for discontinuation. Of the 16 participants who did not complete the 12-month intervention, 8 cited technical issues with MHCE as their primary reason, 6 listed either a time constraint or relocation as their primary reason, and 2 were lost to follow-up. The specific technical issues cited by the 8 participants withdrawing from the study were not fully known. Anecdotal evidence received by the senior research associates suggested that a few patients were frustrated with system upgrades and challenges with occasional manual synching of devices.
Throughout the 12-month study, 20.6\% (21/102) presented new comorbidities in the control group, and $11 \%$ (11/96) of subjects presented new comorbidities in the intervention group $\left(\chi_{1}^{2}=3.2\right.$; $P=.07)$. On the basis of the covariate-adjusted GEE model, the estimated odds of a new comorbidity throughout the study was 2.27 times higher for the control group than for the intervention group $\left(\chi_{1}^{2}=3.9 ; P=.047\right)$.

\section{Phase II-Baseline Characteristics}

Table 3 provides the study baseline demographics and outcomes at baseline. Participants had a mean age of 62.9 (SD 10.3) years, a mean BMI of 32.7 (SD 6.2), and were 61.6\% (141/229) male. Mean $\mathrm{HbA}_{1 \mathrm{c}}$ was in the high range (mean 7.5\%, SD 1.4\%). The mean duration of T2D was 9.8 (SD 7.5) years. The study cohort was well educated; $87.8 \%$ (201/229) attended some college and $55.5 \%(127 / 229)$ had a college degree or higher. In this sample, $10 \%(23 / 229)$ of patients had a baseline PAM level of 1 (14/112, $12.5 \%$ in control group, $9 / 117,7.7 \%$ in intervention group), $14.8 \%(34 / 229)$ had a baseline PAM level of $2(19 / 112,17.0 \%$ in control group, $15 / 117,12.8 \%$ in intervention group), $51.5 \%$ $(118 / 229)$ had a baseline PAM level of $3(55 / 112,49.1 \%$ in the control group, $63 / 117,53.8 \%$ in the intervention group), and $23.6 \%(54 / 229)$ had a baseline PAM level of 4 (24/112, 21.4\% in control group, $30 / 117,25.6 \%$ in intervention group). Between group differences were not statistically significant $(P=.13)$. The control and intervention groups were well balanced on most baseline characteristics, with the exception of work status (unemployment: 77/112, 68.8\% in the control group, 59/117, $50.4 \%$ in the intervention group; full-time employment: $27 / 112$, $24.1 \%$ in control group, $42 / 117,35.9 \%$ in intervention group; $P=.02$ ), baseline low-density lipoprotein (LDL) cholesterol (control group: mean 97.1, SD 39.1; intervention group: mean 80.9 (SD 36.5); $P=.001$ ). Due to this imbalance, we adjust for these variables in all models. 
Table 3. Characteristics of phase II participant demographics and outcomes at baseline.

\begin{tabular}{|c|c|c|c|c|}
\hline \multirow[t]{2}{*}{ Variable } & \multirow[t]{2}{*}{ Total } & \multicolumn{2}{|l|}{ Group } & \multirow[t]{2}{*}{$P$ value } \\
\hline & & Control & Intervention & \\
\hline \multicolumn{5}{|l|}{ Demographics } \\
\hline Age (years), mean $(\mathrm{SD})^{\mathrm{a}}$ & $62.9(10.3)$ & $63.2(9.8)$ & $62.5(10.8)$ & .49 \\
\hline Gender (female), $\mathrm{n}(\%)^{\mathrm{b}}$ & $88(38.4)$ & $49(43.8)$ & $39(33.3)$ & .11 \\
\hline Race, $\mathbf{n}(\%)^{\mathrm{c}}$ & & & & .70 \\
\hline American Indian & $2(0.9)$ & $0(0.0)$ & $2(1.7)$ & \\
\hline Asian & $17(7.4)$ & $8(7.1)$ & $9(7.7)$ & \\
\hline Black & $33(14.4)$ & $14(12.5)$ & $19(16.2)$ & \\
\hline Native Hawaiian & $16(7.0)$ & $7(6.3)$ & $9(7.7)$ & \\
\hline Unknown/unreported & $18(7.9)$ & $8(7.1)$ & $10(8.5)$ & \\
\hline White & $143(62.4)$ & $75(67.0)$ & $68(58.1)$ & \\
\hline Hispanic, $\mathrm{n}(\%)^{\mathrm{b}}$ & $24(10.5)$ & $10(8.9)$ & $14(12.0)$ & .45 \\
\hline Education, $n(\%)^{d}$ & & & & .22 \\
\hline Less than high school & $1(0.4)$ & $1(0.9)$ & $0.0(0.0)$ & \\
\hline High school graduate & $27(11.8)$ & $15(13.4)$ & $12(10.3)$ & \\
\hline Some college, no degree & $74(32.3)$ & $35(31.3)$ & $39(33.3)$ & \\
\hline Associate's degree & $41(17.9)$ & $24(21.4)$ & $17(14.5)$ & \\
\hline Bachelor's degree & $46(20.1)$ & $20(17.9)$ & $26(22.2)$ & \\
\hline Master's degree & $36(15.7)$ & $16(14.3)$ & $20(17.1)$ & \\
\hline Professional degree & $4(1.7)$ & $1(0.9)$ & $3(2.6)$ & \\
\hline Weight (lbs), mean (SD) ${ }^{\mathrm{a}}$ & $210(47.1)$ & $209(50.1)$ & $211(44.2)$ & .50 \\
\hline Height (inches), mean (SD) ${ }^{\mathrm{a}}$ & $67.1(4.0)$ & $67.0(3.8)$ & $67.2(4.2)$ & .44 \\
\hline Duration of type 2 diabetes (years), mean $(\mathrm{SD})^{\mathrm{a}}$ & $9.8(7.5)$ & $10.0(7.6)$ & $9.6(7.4)$ & .69 \\
\hline Current smoker, $\mathrm{n}(\%)^{\mathrm{b}}$ & $15(6.6)$ & $8(7.1)$ & $7(6.0)$ & .72 \\
\hline Hospitalization, $\mathrm{n}(\%)^{\mathrm{b}}$ & 34 (14.8) & $21(18.8)$ & $13(11.1)$ & .10 \\
\hline Emergency room visit, $\mathrm{n}(\%)^{\mathrm{b}}$ & 87 (38.0) & 45 (40.2) & 42 (35.9) & .50 \\
\hline Surgeries, $\mathrm{n}(\%)^{\mathrm{b}}$ & $31(13.5)$ & $14(12.5)$ & $17(14.5)$ & .65 \\
\hline Work status, $\mathrm{n}(\%)^{\mathrm{c}}$ & & & & .02 \\
\hline Unemployed & $136(59.4)$ & 77 (68.8) & $59(50.4)$ & \\
\hline Part-time & $24(10.5)$ & $8(7.1)$ & $16(13.7)$ & \\
\hline Full-time & $69(30.1)$ & $27(24.1)$ & $42(35.9)$ & \\
\hline Family history of cancer, $\mathrm{n}(\%)^{\mathrm{b}}$ & $137(59.8)$ & $72(64.3)$ & $65(55.6)$ & .18 \\
\hline Family history of heart disease, $\mathrm{n}(\%)^{\mathrm{b}}$ & $132(57.6)$ & $64(57.1)$ & $68(58.1)$ & .88 \\
\hline Family history of high Blood pressure, $\mathrm{n}(\%)^{\mathrm{b}}$ & $164(71.6)$ & 78 (69.6) & $86(73.5)$ & .52 \\
\hline Family history of high cholesterol, $\mathrm{n}(\%)^{\mathrm{b}}$ & $111(48.5)$ & $55(49.1)$ & $56(47.9)$ & .85 \\
\hline Site=Madigan, $\mathrm{n}(\%)^{\mathrm{b}}$ & $113(49.3)$ & $51(45.5)$ & $62(53.0)$ & .26 \\
\hline $\mathbf{P A M}^{\mathrm{e}}, \mathbf{n}(\%)^{\mathrm{d}}$ & & & & .13 \\
\hline Level 1 & $23(10.0)$ & $14(12.5)$ & $9(7.7)$ & \\
\hline
\end{tabular}




\begin{tabular}{|c|c|c|c|c|}
\hline \multirow[t]{2}{*}{ Variable } & \multirow[t]{2}{*}{ Total } & \multicolumn{2}{|l|}{ Group } & \multirow[t]{2}{*}{$P$ value } \\
\hline & & Control & Intervention & \\
\hline Level 2 & $34(14.8)$ & $19(17.0)$ & $15(12.8)$ & \\
\hline Level 3 & $118(51.5)$ & $55(49.1)$ & $63(53.8)$ & \\
\hline Level 4 & $54(23.6)$ & $24(21.4)$ & $30(25.6)$ & \\
\hline \multicolumn{5}{|l|}{ Outcomes } \\
\hline $\mathrm{PAM}$, mean $(\mathrm{SD})^{\mathrm{a}}$ & $63.2(12.8)$ & $62.8(13.5)$ & $63.6(12.2)$ & .56 \\
\hline Summary of Diabetes Self-Care Activities score, mean (SD) ${ }^{a}$ & $37.5(14.0)$ & $38.0(14.3)$ & $37.1(13.8)$ & .58 \\
\hline Glycated hemoglobin, mean $(\mathrm{SD})^{\mathrm{a}}$ & $7.5(1.4)$ & $7.6(1.6)$ & $7.5(1.3)$ & .95 \\
\hline $\mathrm{BMI}$, mean $(\mathrm{SD})^{\mathrm{a}}$ & $32.7(6.2)$ & $32.6(6.8)$ & $32.8(5.7)$ & .77 \\
\hline Waist (inches), mean (SD) ${ }^{\mathrm{a}}$ & $44.1(5.9)$ & $43.9(6.4)$ & $44.2(5.4)$ & 63 \\
\hline Diastolic BP (mm Hg), mean (SD) ${ }^{\mathrm{a}}$ & $79.5(9.6)$ & $80.7(9.4)$ & $78.4(9.7)$ & .09 \\
\hline Systolic BP $(\mathrm{mm} \mathrm{Hg})$, mean $(\mathrm{SD})^{\mathrm{a}}$ & $133(17.6)$ & $134(17.9)$ & $131(17.3)$ & .25 \\
\hline High-density lipoprotein cholesterol (mg/dL), mean (SD) ${ }^{\mathrm{a}}$ & $45.2(13.6)$ & $46.6(15.4)$ & $43.8(11.3)$ & .47 \\
\hline Low-density lipoprotein cholesterol $(\mathrm{mg} / \mathrm{dL})$, mean $(\mathrm{SD})^{\mathrm{a}}$ & $88.9(38.6)$ & $97.1(39.1)$ & $80.9(36.5)$ & .001 \\
\hline
\end{tabular}

${ }^{\mathrm{a}}$ Continuous variables compared using Wilcoxon/Kruskal-Wallis test.

${ }^{\mathrm{b}}$ Binary variables compared using chi-square test.

${ }^{\mathrm{c}}$ Nominal variables compared using Fisher exact test.

${ }^{\mathrm{d}}$ Ordinal variables compared using Cochran-Armitage trend test.

ePAM: Patient Activation Measure.

\section{Phase II-Primary Outcomes}

Within- and between-group comparisons based on GEE are displayed in Table 4. For each intervention group, we assessed changes in the outcome between baseline and month 6 and baseline and month 12 . For each group, CIs that exclude 0 indicate a significant change in the outcome between baseline and a given month. $P$ values $<.05$ indicate that this change in the outcome was significantly different between the intervention and control groups. At months 6 and 12, statistically significant improvements were seen in the control group for PAM (month 6: control group improvement $=4.81,95 \% \mathrm{CI} 2.21$ to 7.42 ; month 12: control group improvement=7.49, 95\% CI 4.44 to 10.55 ). That is, improvement in PAM for the control group was 4.81 between baseline and month 6 and 7.49 between baseline and month 12. Although the intervention group showed slight improvement in PAM, these improvements were not statistically

significant (month 6: intervention group improvement $=1.57$, $95 \% \mathrm{CI}-1.34$ to 4.48 ; month 12 : intervention group improvement $=1.77,95 \% \mathrm{CI}-1.02$ to 4.57 ). The improvement in the control group was significantly greater than the improvement in the intervention group at month 12 only (month 6: between-group difference $=3.24 ; P=.10$ and month 12: between-group difference $=5.72 ; P=.007$ ).

For each group, estimates (and the corresponding CIs) are given for the change in outcome between month 6 and baseline and month 12 and baseline. CIs that exclude 0 indicate statistically significant within-group change between a given month (ie, month 6 or 12) and baseline. The first $P$ value column corresponds to testing whether the change in outcomes between month 6 and baseline is different between the 2 groups. The second $P$ value column corresponds to testing whether the change in outcomes between month 12 and baseline is different between the 2 groups. 
Table 4. Analysis of change from baseline at midpoint and study end.

\begin{tabular}{|c|c|c|c|c|c|c|}
\hline \multirow[t]{2}{*}{ Outcome } & \multicolumn{3}{|l|}{ Month 6} & \multicolumn{3}{|l|}{ Month 12} \\
\hline & $\begin{array}{l}\text { Control, OR }{ }^{\mathrm{a}}(95 \% \\
\text { CI) }\end{array}$ & $\begin{array}{l}\text { Intervention, OR } \\
(95 \% \mathrm{CI})\end{array}$ & $P$ value & Control, OR (95\% CI) & $\begin{array}{l}\text { Intervention, OR } \\
(95 \% \mathrm{CI})\end{array}$ & $P$ value \\
\hline $\begin{array}{l}\text { Patient Activation Measure } \\
\text { score }\end{array}$ & $4.81(2.21$ to 7.42$)$ & $1.57(-1.34$ to 4.48$)$ & .10 & $7.49(4.44$ to 10.55$)$ & $1.77(-1.02$ to 4.57$)$ & .007 \\
\hline $\begin{array}{l}\text { Summary of Diabetes Self-Care } \\
\text { Activities score }\end{array}$ & $7.52(5.43$ to 9.61$)$ & $7.52(5.30$ to 9.73$)$ & $>.99$ & $6.97(4.40$ to 9.55$)$ & 7.52 (5.06 to 9.97$)$ & .77 \\
\hline Glycated hemoglobin & $\begin{array}{l}-0.36(-0.57 \text { to } \\
-0.14)\end{array}$ & $-0.18(-0.36$ to 0.01$)$ & .21 & $\begin{array}{l}-0.53(-0.78 \text { to } \\
-0.29)\end{array}$ & $-0.11(-0.28$ to 0.07$)$ & .006 \\
\hline $\operatorname{BMI}\left(\mathrm{kg} / \mathrm{m}^{2}\right)$ & $-0.31(-0.62$ to 0.00$)$ & $\begin{array}{l}-0.28(-0.53 \text { to } \\
-0.02)\end{array}$ & .86 & $\begin{array}{l}-0.45(-0.82 \text { to } \\
-0.07)\end{array}$ & $\begin{array}{l}-0.36(-0.62 \text { to } \\
-0.10)\end{array}$ & .72 \\
\hline Waist (inches) & $\begin{array}{l}-0.57(-0.96 \text { to } \\
-0.19)\end{array}$ & $\begin{array}{l}-0.76(-1.09 \text { to } \\
-0.44)\end{array}$ & .46 & $\begin{array}{l}-1.46(-1.95 \text { to } \\
-0.98)\end{array}$ & $\begin{array}{l}-1.49(-1.90 \text { to } \\
-1.07)\end{array}$ & .95 \\
\hline $\begin{array}{l}\text { Diastolic blood pressure (mm } \\
\mathrm{Hg})\end{array}$ & $-1.83(-3.81$ to 0.15$)$ & $-0.58(-2.30$ to 1.14$)$ & .35 & $\begin{array}{l}-2.18(-3.98 \text { to } \\
-0.38)\end{array}$ & $\begin{array}{l}-1.72(-3.22 \text { to } \\
-0.22)\end{array}$ & .70 \\
\hline $\begin{array}{l}\text { Systolic blood pressure }(\mathrm{mm} \\
\mathrm{Hg})\end{array}$ & $-2.90(-6.31$ to 0.52$)$ & $0.57(-3.13$ to 4.26$)$ & .18 & -2.88 ( -6.63 to 0.87$)$ & $-1.63(-4.99$ to 1.74$)$ & .63 \\
\hline $\begin{array}{l}\text { High-density lipoproteincholes- } \\
\text { terol }(\mathrm{mg} / \mathrm{dL})\end{array}$ & $1.22(-0.12$ to 2.57$)$ & $1.59(-0.39$ to 3.58$)$ & .76 & $-1.39(-2.82$ to 0.03$)$ & $-0.26(-2.26$ to 1.74$)$ & .37 \\
\hline $\begin{array}{l}\text { Low-density lipoprotein } \\
\text { cholesterol (mg/dL) }\end{array}$ & $\begin{array}{l}-5.78(-11.22 \text { to } \\
-0.33)\end{array}$ & $0.12(-5.69$ to 5.93$)$ & .15 & $\begin{array}{l}-7.14(-13.43 \text { to } \\
-0.85)\end{array}$ & $4.38(-2.16$ to 10.91$)$ & .01 \\
\hline
\end{tabular}

${ }^{\mathrm{a} O R}$ : odds ratio.

\section{Phase II-Secondary Outcomes}

At month 6, the control group exhibited statistically significant improvements in $\mathrm{HbA}_{1 \mathrm{c}}$ and LDL cholesterol (as indicated by the CIs in the first column of Table 4). Both intervention and control groups exhibited statistically significant improvements in SDSCA, BMI, and waist size. However, the differences between the intervention and control groups on improvements in these outcomes were not significantly different at month 6 (as indicated by $P$ values $>.05$ in the third column of Table 4). At month 12, statistically significant improvements occurred in SDSCA, BMI, waist size, and diastolic blood pressure in both the intervention and control groups. The control group also exhibited significant improvements in $\mathrm{HbA}_{1 \mathrm{c}}$ and LDL cholesterol at month 12 , and these improvements were significantly greater compared with those of the intervention group $\left(\mathrm{HbA}_{1 \mathrm{c}}\right.$ : between-group difference=-0.42;P=.006 and LDL cholesterol: between-group difference $=-11.52 ; P=.01)$.

\section{Phase II-Stratified Analyses by Baseline Patient Activation Measure Level}

The intervention is tailored according to baseline PAM level, and therefore, we expect the effect of intervention over time to differ by subjects' baseline PAM level. To test this, a three-way interaction term for the intervention group, time, and baseline PAM level was incorporated into the above GEE models. The results for the change between baseline and end of study (month
12) for each group, stratified by baseline PAM level, are presented in Tables 5 and 6.

Within each baseline PAM level, estimates (and corresponding CIs) are given for the change in outcome between month 12 and baseline for both the intervention and control groups. CIs that exclude 0 indicate statistically significant within-group change between month 12 and baseline for subjects in a given PAM level. The $P$ value column corresponds to testing whether the change in outcomes is different between the intervention and control groups within a given PAM level.

Among subjects with baseline PAM level 1, both intervention and control groups exhibited significant improvements in PAM score at month 12 (control group improvement $=20.38,95 \% \mathrm{CI}$ 13.05 to 27.71 ; intervention group improvement $=15.93,95 \%$ CI 8.99 to 22.87); however, between-group differences did not reach statistical significance $(P=.39)$. On secondary outcomes, the control group exhibited significant improvements in waist size, diastolic, and systolic blood pressure. The intervention group exhibited significant improvements in SDSCA, $\mathrm{HbA}_{1 \mathrm{c}}$, BMI, waist size, and HDL cholesterol. Statistically significant between-group differences occurred only in $\mathrm{HbA}_{1 \mathrm{c}}$, BMI, and HDL cholesterol, indicating that the intervention group exhibited greater improvement in these outcomes compared with the control group $\left(\mathrm{HbA}_{1 \mathrm{c}}\right.$ : between-group difference $=-0.43, P=.04$; BMI: between-group difference $=-1.80, P=.01$; HDL cholesterol: between-group difference $=8.42, P<.001)$. 
Table 5. Analysis of change from baseline to study end by baseline Patient Activation Measure level.

\begin{tabular}{|c|c|c|c|c|c|c|}
\hline \multirow[t]{2}{*}{ Outcome } & \multicolumn{3}{|l|}{ Baseline PAM $^{\mathrm{a}}$ level 1} & \multicolumn{3}{|l|}{ Baseline PAM level 2} \\
\hline & Control, $\mathrm{OR}^{\mathrm{b}}(95 \% \mathrm{CI})$ & $\begin{array}{l}\text { Intervention, OR (95\% } \\
\mathrm{CI})\end{array}$ & $P$ value & Control, OR (95\% CI) & $\begin{array}{l}\text { Intervention, OR (95\% } \\
\text { CI) }\end{array}$ & $P$ value \\
\hline PAM score & 20.38 (13.05 to 27.71$)$ & 15.93 (8.99 to 22.87 ) & .39 & 13.09 (6.26 to 19.92$)$ & 7.66 (3.33 to 11.99$)$ & .19 \\
\hline $\begin{array}{l}\text { Summary of Diabetes } \\
\text { Self-Care Activities score }\end{array}$ & $8.99(-1.49$ to 19.48$)$ & 12.78 (3.71 to 21.85$)$ & .59 & $6.42(0.49$ to 12.36$)$ & 11.09 (6.84 to 15.34$)$ & .21 \\
\hline Glycated hemoglobin & $-0.09(-0.33$ to 0.16$)$ & $-0.52(-0.87$ to -0.18$)$ & .04 & $-1.04(-1.88$ to -0.20$)$ & $-0.09(-0.59$ to 0.42$)$ & .06 \\
\hline BMI $\left(\mathrm{kg} / \mathrm{m}^{2}\right)$ & $0.58(-0.37$ to 1.53$)$ & $-1.22(-2.21$ to -0.23$)$ & .01 & $-0.54(-1.28$ to 0.20$)$ & $0.13(-0.63$ to 0.90$)$ & .22 \\
\hline Waist (inches) & $-1.50(-2.73$ to -0.27$)$ & $-1.98(-3.32$ to -0.64$)$ & .61 & $-1.42(-2.36$ to -0.47$)$ & $-1.90(-3.30$ to -0.51$)$ & .57 \\
\hline $\begin{array}{l}\text { Diastolic blood pressure } \\
(\mathrm{mm} \mathrm{Hg})\end{array}$ & $-4.00(-7.86$ to -0.14$)$ & $-3.89(-10.79$ to 3.01$)$ & .98 & $-3.22(-7.38$ to 0.95$)$ & $-0.50(-4.18$ to 3.18$)$ & .34 \\
\hline $\begin{array}{l}\text { Systolic blood pressure } \\
(\mathrm{mm} \mathrm{Hg})\end{array}$ & $-9.93(-17.18$ to -2.68$)$ & $-8.33(-17.17$ to 0.51$)$ & .78 & $5.86(-3.95$ to 15.67$)$ & $-2.42(-10.76$ to 5.92$)$ & .21 \\
\hline $\begin{array}{l}\text { High-density lipoprotein } \\
\text { cholesterol (mg/dL) }\end{array}$ & $-4.86(-8.16$ to -1.56$)$ & $3.56(0.50$ to 6.61$)$ & $<.001$ & $1.40(-3.22$ to 6.02$)$ & $-2.76(-6.30$ to 0.77$)$ & .16 \\
\hline $\begin{array}{l}\text { Low-density lipoprotein } \\
\text { cholesterol (mg/dL) }\end{array}$ & $-10.21(-25.74$ to 5.31$)$ & $9.56(-10.02$ to 29.13$)$ & .12 & $-5.62(-24.94$ to 13.70$)$ & $10.55(-12.21$ to 33.30$)$ & .29 \\
\hline
\end{tabular}

${ }^{\mathrm{a}}$ PAM: Patient Activation Measure.

${ }^{\mathrm{b}} \mathrm{OR}$ : odds ratio.

Table 6. Analysis of change from baseline to study end baseline Patient Activation Measure level (continued).

\begin{tabular}{|c|c|c|c|c|c|c|}
\hline \multirow[t]{2}{*}{ Outcome } & \multicolumn{3}{|l|}{ Baseline PAM $^{\mathrm{a}}$ level 3} & \multicolumn{3}{|l|}{ Baseline PAM level 4} \\
\hline & Control, $\mathrm{OR}^{\mathrm{b}}(95 \% \mathrm{CI})$ & $\begin{array}{l}\text { Intervention, OR (95\% } \\
\text { CI) }\end{array}$ & $P$ value & Control, OR (95\% CI) & $\begin{array}{l}\text { Intervention, OR (95\% } \\
\text { CI) }\end{array}$ & $P$ value \\
\hline PAM score & $6.29(2.24$ to 10.35$)$ & $4.26(0.88$ to 7.64$)$ & .45 & $-1.44(-7.39$ to 4.50$)$ & $\begin{array}{l}-10.49(-16.54 \text { to } \\
-4.44)\end{array}$ & .04 \\
\hline $\begin{array}{l}\text { Summary of Diabetes } \\
\text { Self-Care Activities score }\end{array}$ & $6.49(2.75$ to 10.23$)$ & $7.58(4.44$ to 10.73$)$ & .66 & $7.02(3.15$ to 10.89$)$ & $3.95(-1.76$ to 9.66$)$ & .38 \\
\hline Glycated hemoglobin & $-0.49(-0.83$ to -0.16$)$ & $-0.04(-0.25$ to 0.16$)$ & .02 & $-0.57(-1.11$ to -0.03$)$ & $-0.09(-0.55$ to 0.36$)$ & .18 \\
\hline BMI $\left(\mathrm{kg} / \mathrm{m}^{2}\right)$ & $-0.43(-0.86$ to 0.01$)$ & $-0.42(-0.76$ to -0.07$)$ & .97 & $-1.25(-2.47$ to -0.04$)$ & $-0.09(-0.53$ to 0.35$)$ & .08 \\
\hline Waist (inches) & $-1.51(-2.18$ to -0.83$)$ & $-1.56(-2.08$ to -1.03$)$ & .91 & $-1.37(-2.63$ to -0.10$)$ & $-0.90(-1.71$ to -0.08$)$ & .54 \\
\hline $\begin{array}{l}\text { Diastolic blood pressure } \\
(\mathrm{mm} \mathrm{Hg})\end{array}$ & $-2.55(-5.22$ to 0.11$)$ & $-1.23(-3.24$ to 0.79$)$ & .44 & $-0.19(-4.24$ to 3.86$)$ & $-2.22(-5.41$ to 0.96$)$ & .44 \\
\hline $\begin{array}{l}\text { Systolic blood pressure } \\
(\mathrm{mm} \mathrm{Hg})\end{array}$ & $-4.33(-9.20$ to 0.53$)$ & $-1.58(-6.34$ to 3.19$)$ & .43 & $-2.78(-12.44$ to 6.89$)$ & $1.69(-5.17$ to 8.56$)$ & .46 \\
\hline $\begin{array}{l}\text { High-density lipoprotein } \\
\text { cholesterol (mg/dL) }\end{array}$ & $-0.93(-2.84$ to 0.99$)$ & $0.12(-2.56$ to 2.81$)$ & .53 & -2.44 ( -4.91 to 0.02$)$ & $-1.03(-6.10$ to 4.05$)$ & .62 \\
\hline $\begin{array}{l}\text { Low-density lipoprotein } \\
\text { cholesterol (mg/dL) }\end{array}$ & $-3.99(-12.36$ to 4.37$)$ & $3.32(-3.62$ to 10.26$)$ & .19 & $-13.38(-27.02$ to 0.25$)$ & $-0.19(-17.09$ to 16.70$)$ & .23 \\
\hline
\end{tabular}

${ }^{\mathrm{a}}$ PAM: Patient Activation Measure.

${ }^{\mathrm{b}} \mathrm{OR}$ : odds ratio.

Among subjects with baseline PAM levels 2 and 3, both the intervention and control groups exhibited significant improvements in PAM, SDSCA, and waist size. However, between-group differences were not statistically significant. The control group also exhibited significant improvements in $\mathrm{HbA}_{1 \mathrm{c}}$; between-group differences were significant among those with baseline PAM level 3 only (between-group difference $=-0.45 ; P=.02)$. The intervention group also exhibited significant improvement in BMI among subjects with PAM level 3, but the between-group differences did not reach statistical significance.

Among subjects with baseline PAM level 4, the intervention group exhibited a significant decrease in PAM (intervention group change $=-10.49 ; 95 \%$ CI -16.54 to -4.44$)$, whereas control subjects exhibited no significant change (control group 
change $=-1.44 ; 95 \% \mathrm{CI}-7.39$ to 4.50$)$. This difference in change was statistically significant (between-group difference $=-9.05$; $P=.04$ ). The control group exhibited significant improvements in SDSCA, $\mathrm{HbA}_{1 \mathrm{c}}$, and BMI. Both groups exhibited significant improvements in waist size. However, between-group differences did not reach statistical significance in these outcomes.

\section{Phase II-Participant Engagement and Usability}

The percentage of subjects who engaged with MHCE at least $50 \%$ of the days in each time period was $60.7 \%$ (68/112) for months $0-3,57.4 \%$ (62/108) for months $3-6,49.5 \%$ (51/103) for months 6-9, and $43 \%$ (42/98) for months 9-12. The percentage of subjects who engaged with MHCE at least $80 \%$ of the days in each time period was $41.1 \%$ (46/112) for months $0-3,41.7 \%$ (45/108) for months 3-6, 14.6\% (15/103) for months 6-9, and 26\% (25/98) for months 9-12. Strong adherence, defined engagement with MHCE on at least $80 \%$ of days in each time period, was associated with improvement in all outcomes. However, only the association with $\mathrm{HbA}_{1 \mathrm{c}}$ reached statistical significance (mean improvement $=0.35 ; P=.049$ ).

The mean SUS score for the MHCE group was 75.6 (SD 17.3) at month 6 and 76.8 (SD 14.8) at month 12. Strong adherence was associated with a higher SUS score (average increase $=5.01$; $P=.04)$. As SUS was not recorded for the control group, group differences could not be compared.

\section{Discussion}

\section{Principal Findings}

The primary goal of this large feasibility study was to enhance the PAM level and improve self-management of T2D care using the DoD's interactive and tailored MHCE system for T2D in a PCMH setting. To this end, we hypothesized that a user-centered design process would successfully shape the development of the MHCE for use in the self-management of T2D care. The research team engaged both patients and clinicians, observing patient and clinician overall satisfaction with the MHCE, high SUS (A+ and A-) scores, and 29 offered recommendations for system improvement; $86 \%(25 / 29)$ of these recommendations resulted in intervention modifications before feasibility testing. The methods and findings from the study's phase I research align well with the aging barriers addressed by Wildenbos et al [61]. These include cognitive, physical ability, perception, and motivational barriers.

When comparing this study with comparable mHealth studies, there were differences in participant demographics. Specifically, our research participants tended to be older (age: mean 62.9 years, SD 10.3) than participants in other studies [36,38,62-69] and had a larger BMI $\left(32.7 \mathrm{~kg} / \mathrm{m}^{2}\right.$, SD $\left.6.2 \mathrm{~kg} / \mathrm{m}^{2}\right)$ at baseline [62,64-66,68]. This study engaged a substantial percentage, $59.4 \%$ (136/229), of unemployed participants; most of them were military retirees. Finally, our research participants were members of a PCMH site within one of two military treatment facilities (ie, military run hospitals) and as such typically received health care services with no (or minimal) out-of-pocket costs. A descriptive primer on this federal health system has been published [70].
Overall retention was high in this study, 93.0\% (213/229) for the 12-month study, which is consistent with other mHealth projects [66] and demonstrates the feasibility of conducting a PCMH intervention among T2D patients. The 12-month duration of this study was longer than loosely comparable studies, which generally targeted a 9-month [36,63], 6-month [64,65], or 3-month duration [38,62].

The team hypothesized that the use of the MHCE would increase the PAM and self-care activities of patients with T2D and that patients who engage at a higher rate with the MHCE would realize improvement in clinical measures. In our study, both intervention and intervention-lite (control) groups showed significant improvement from baseline to 12 months in SDSCA (measuring self-care activities) as well as in BMI, waist size, and diastolic blood pressure control. A somewhat surprising finding in the study is that only the control group exhibited significant improvement in the PAM score. Furthermore, improvements in the control group exceeded improvements in the intervention group for most clinical outcomes.

However, a closer analysis of the data reveals a complex yet intriguing pattern of how mHealth intervention effectiveness can vary by the baseline level of patient activation. With the exception of patients with the highest level of activation (PAM level 4), all intervention group patients exhibited significant improvements in the PAM score. Furthermore, the intervention appears to be superior to control for patients with the lowest level of activation (PAM level 1). In this class of patients, the intervention group showed significantly greater improvements at the end of the study in $\mathrm{HbA}_{1 \mathrm{c}}, \mathrm{BMI}$, and HDL cholesterol levels compared with the control group (these were the only significant differences between the groups). This finding may suggest that in a resource-limited health system environment, a targeted investment in mHealth to support self-management of T2D for PAM level 1 patients may yield optimal results compared with patients who are more activated. With the more activated patient, demonstrating higher PAM scores, a less costly peripheral device (eg, glucometer, activity monitor, and scale) may by itself enhance self-care activities.

Our finding that the intervention group exhibited significant improvements over the control group in several cardiovascular outcomes in T2D patients with baseline PAM level 1 is consistent with previous findings that text messaging is effective in helping patients with T2D achieve better glycemic control [16,36,71]. Although tailored messaging did not generate superior results compared with the control group for patients with higher PAM levels, it does not suggest that the PAM-aligned tailored behavioral messaging was faulty or should be discarded. In our study, the DoD technology partners secured the tailored behavioral messaging embedded within the MHCE under an indicator labeled as "health tips." However, because of privacy concerns, patients could only see the message after logging into the MHCE mobile app through its security layers to view the message. The multistep process of accessing the messages was indirect and could have been overlooked on the patients' personal cell phone. Future efforts should consider redesigning the MHCE (or mHealth platforms) to accommodate nonpersonal health information (PHI) and tailored health 
message delivery to the patient in his/her preferred communication process. Most of this will likely be via mobile app push notifications and/or text messaging. Several published studies have successfully leveraged tailored health messaging (without PHI), delivered in a direct delivery process via text messaging to participants $[16,36,69]$; one study was very short term in nature [69].

Although SUSs remained constant throughout the study and were associated with increased patient engagement, overall patient engagement with the MHCE system decreased throughout the study period. Decreased engagement may be partly explained by frustration with system upgrades and synching of devices expressed by some patients, along with the multistep process of MHCE discussed above. However, high levels of initial patient engagement in other mHealth projects that drop off after 6 to 12 months have been observed $[16,63,72]$. This might suggest that systems such as the MHCE may be optimally deployed in self-care of T2D for periods up to about 6 months; lengthy engagement ( $>6$ months) may not generate the desired results.

\section{Limitations}

Our study design is not immune from potential threats to validity. Both the intervention and control groups were issued the same clinical outcome measuring devices and completed the biweekly SDSCA survey. However, we do not have information on whether patients in the control group did the synchronization of their measuring devices to their mobile phones, tablet computers, or desktop/laptop computers for viewing and tracking purposes. Therefore, we cannot rule out the possibility that a substantial proportion of the control group had access to visualized tracking information similar to the intervention group. For these patients, improvement in these outcomes may be explained by the same mechanisms whereby self-weighing is linked with weight loss [73]. Another limitation of the study is that food intake and daily activities outside the research sites are uncontrolled due to the nature of this type of field experiment.

Finally, although our study included user-center design testing (including solicitation of user design preferences) and ultimately generated a high retention rate for the 12-month study, patient engagement with MHCE decreased throughout the course of the phase II study. This trend was also seen in previous mHealth projects, and future studies should therefore consider incorporating follow-up participant assessments of continued engagement. If implemented following phase I, this may help the understanding of discontinued engagement and provide opportunities for improvement.

\section{Acknowledgments}

Research was extramurally funded by the US Army Medical Research Acquisition Activity contract \#W81XWH-15-C-0070. The funder did not influence the design of the study or strategies related to its collection, analysis, or interpretation. The views expressed are those of the authors and do not reflect the official policy of the US Department of the Army, the Department of the Air Force, the Department of Defense, or the US Federal Government.

\section{Authors' Contributions}

RG initially conceptualized the study, and both RG and LR wrote the initial draft of the manuscript. PC, RG, KE, MH, KC, and JM assisted in the setting of the narrative, enrollment strategies, and institutional review board-related issues. The technical aspects of the intervention and MHCE description were authored by JL and RG. The biostatistics and data analysis strategies were developed by LC, LS, and LR. The patient activation activities in the study were coordinated by MH, KC, JM, AS, KP, and KE. The user-centered design and qualitative component were researched and authored by JW, SG, and KE. The outcome measures component was conceptualized and authored by PC, KT, LS, LZ, JW, LC, MH, and KE. The clinical components, including the inclusion and exclusion criteria, were developed by PC, JM, MH, KE, and RG. The Military Health System review and components were authored by JM, MH, KE, and RG. Active site Principal Investigators in the study were PC and RM. Acquisition and formatting of data for analysis were conducted by KT, LC, MA, and EH. Statistical analyses were conducted by LR, KT, BL, and LS. Interpretation of the data was performed by LR, RG, LS, and KT. All authors read, contributed to, critically reviewed, and approved the final manuscript.

\section{Conflicts of Interest}

JL and AS are federal employees charged with oversight of the DoD's MHCE mHealth system used in the study. None of the other authors report any conflicts of interest.

\section{Multimedia Appendix 1}

Annotated visual presentation of patient screenshots and workflow. [PPTX File, 5193 KB-Multimedia Appendix 1]

\section{Multimedia Appendix 2}

Annotated visual presentation of clinician access. [PPTX File, 4989 KB-Multimedia Appendix 2] 


\section{Multimedia Appendix 3}

Phase I data collection instrument.

[PDF File (Adobe PDF File), 195 KB-Multimedia Appendix 3]

\section{Multimedia Appendix 4}

Clinician focus group - facilitator's guide.

[PDF File (Adobe PDF File), 125 KB-Multimedia Appendix 4]

\section{Multimedia Appendix 5}

Mobile Health Care Environment modifications report to funder.

[PDF File (Adobe PDF File), 585 KB-Multimedia Appendix 5]

\section{Multimedia Appendix 6}

Standards, alerts and safety algorithms report.

[PDF File (Adobe PDF File), 211 KB-Multimedia Appendix 6]

\section{References}

1. Sudore RL, Karter AJ, Huang ES, Moffet HH, Laiteerapong N, Schenker Y, et al. Symptom burden of adults with type 2 diabetes across the disease course: diabetes \& aging study. J Gen Intern Med 2012 Dec;27(12):1674-1681 [FREE Full text] [doi: 10.1007/s11606-012-2132-3] [Medline: 22854982]

2. Vigersky RA. An overview of management issues in adult patients with type 2 diabetes mellitus. J Diabetes Sci Technol 2011 Mar 1;5(2):245-250 [FREE Full text] [doi: 10.1177/193229681100500207] [Medline: 21527089]

3. Centers for Disease Control and Prevention. 2018. Division of Diabetes Translation At A Glance URL: $\underline{\text { https://www.cdc.gov/ }}$ chronicdisease/resources/publications/aag/diabetes.htm [accessed 2019-11-01]

4. Scollan-Koliopoulos M, Bleich D, Rapp KJ, Wong P, Hofmann CJ, Raghuwanshi M. Health-related quality of life, disease severity, and anticipated trajectory of diabetes. Diabetes Educ 2013;39(1):83-91. [doi: 10.1177/0145721712467697] [Medline: 23174664]

5. Wang Y, Xue H, Huang Y, Huang L, Zhang D. A systematic review of application and effectiveness of mhealth interventions for obesity and diabetes treatment and self-management. Adv Nutr 2017 May;8(3):449-462 [FREE Full text] [doi: 10.3945/an.116.014100] [Medline: 28507010]

6. Fatehi F, Gray LC, Russell AW. Mobile health (mhealth) for diabetes care: opportunities and challenges. Diabetes Technol Ther 2017 Jan;19(1):1-3. [doi: 10.1089/dia.2016.0430] [Medline: 28099051]

7. Snider JT, Sullivan J, van Eijndhoven E, Hansen MK, Bellosillo N, Neslusan C, et al. Lifetime benefits of early detection and treatment of diabetic kidney disease. PLoS One 2019;14(5):e0217487 [FREE Full text] [doi: 10.1371/journal.pone.0217487] [Medline: 31150444]

8. Avogaro A, Fadini GP. Microvascular complications in diabetes: a growing concern for cardiologists. Int J Cardiol 2019 Sep 15;291:29-35. [doi: 10.1016/j.ijcard.2019.02.030] [Medline: 30833106]

9. American Diabetes Association. Economic costs of diabetes in the US In 2017. Diabetes Care 2018 May;41(5):917-928 [FREE Full text] [doi: 10.2337/dci18-0007] [Medline: 29567642]

10. Arora S, Peters AL, Agy C, Menchine M. A mobile health intervention for inner city patients with poorly controlled diabetes: proof-of-concept of the TExT-MED program. Diabetes Technol Ther 2012 Jun;14(6):492-496. [doi: 10.1089/dia.2011.0252] [Medline: 22524591]

11. Mohsin AH, Zaidan AA, Zaidan BB, Albahri OS, Albahri AS, Alsalem MA, et al. Based medical systems for patient's authentication: towards a new verification secure framework using CIA standard. J Med Syst 2019 May 22;43(7):192. [doi: 10.1007/s10916-019-1264-y] [Medline: $\underline{31115768]}$

12. Capozza K, Woolsey S, Georgsson M, Black J, Bello N, Lence C, et al. Going mobile with diabetes support: a randomized study of a text message-based personalized behavioral intervention for type 2 diabetes self-care. Diabetes Spectr 2015 May;28(2):83-91 [FREE Full text] [doi: 10.2337/diaspect.28.2.83] [Medline: 25987806]

13. Sahin C, Courtney KL, Naylor PJ, Rhodes RE. Tailored mobile text messaging interventions targeting type 2 diabetes self-management: a systematic review and a meta-analysis. Digit Health 2019;5:2055207619845279 [FREE Full text] [doi: 10.1177/2055207619845279] [Medline: $\underline{\text { 31041110] }}$

14. Borrelli B, Henshaw M, Endrighi R, Adams WG, Heeren T, Rosen RK, et al. An interactive parent-targeted text messaging intervention to improve oral health in children attending urban pediatric clinics: feasibility randomized controlled trial. JMIR Mhealth Uhealth 2019 Nov 11;7(11):e14247 [FREE Full text] [doi: 10.2196/14247] [Medline: $\underline{31710306}$ ] 
15. Kruse C, Betancourt J, Ortiz S, Luna SM, Bamrah IK, Segovia N. Barriers to the use of mobile health in improving health outcomes in developing countries: systematic review. J Med Internet Res 2019 Oct 9;21(10):e13263 [FREE Full text] [doi: 10.2196/13263] [Medline: 31593543 ]

16. McGill DE, Volkening LK, Butler DA, Wasserman RM, Anderson BJ, Laffel LM. Text-message responsiveness to blood glucose monitoring reminders is associated with HbA benefit in teenagers with type 1 diabetes. Diabet Med 2019 May;36(5):600-605. [doi: 10.1111/dme.13929] [Medline: 30734361]

17. Chung S, Panattoni L, Chi J, Palaniappan L. Can secure patient-provider messaging improve diabetes care? Diabetes Care 2017 Oct;40(10):1342-1348. [doi: 10.2337/dc17-0140] [Medline: 28807977]

18. Sun R, Korytkowski MT, Sereika SM, Saul MI, Li D, Burke LE. Patient portal use in diabetes management: literature review. JMIR Diabetes 2018 Nov 6;3(4):e11199 [FREE Full text] [doi: 10.2196/11199] [Medline: 30401665]

19. Gram IT, Larbi D, Wangberg SC. Comparing the efficacy of an identical, tailored smoking cessation intervention delivered by mobile text messaging versus email: randomized controlled trial. JMIR Mhealth Uhealth 2019 Sep 27;7(9):e12137 [FREE Full text] [doi: 10.2196/12137] [Medline: 31573935]

20. Ukoha EP, Feinglass J, Yee LM. Disparities in electronic patient portal use in prenatal care: retrospective cohort study. $\mathbf{J}$ Med Internet Res 2019 Sep 23;21(9):e14445 [FREE Full text] [doi: 10.2196/14445] [Medline: 31586367]

21. Gimbel R, Shi L, Williams JE, Dye CJ, Chen L, Crawford P, et al. Enhancing mhealth technology in the patient-centered medical home environment to activate patients with type 2 diabetes: a multisite feasibility study protocol. JMIR Res Protoc 2017 Mar 6;6(3):e38 [FREE Full text] [doi: 10.2196/resprot.6993] [Medline: 28264792]

22. Greene J, Hibbard JH, Sacks R, Overton V, Parrotta CD. When patient activation levels change, health outcomes and costs change, too. Health Aff (Millwood) 2015 Mar;34(3):431-437. [doi: 10.1377/hlthaff.2014.0452] [Medline: 25732493]

23. Mattingly TJ, Tom SE, Stuart B, Onukwugha E. Examining patient-provider relationship (PPR) quality and patient activation in the medicare population. Aging Clin Exp Res 2017 Jun;29(3):543-548. [doi: 10.1007/s40520-016-0600-z] [Medline: 27324691]

24. Cronin R, Dorner T, Utrankar A, Allen W, Rodeghier M, Kassim A, et al. Increased patient activation is associated with fewer emergency room visits and hospitalizations for pain in adults with sickle cell disease. Pain Med 2019 Aug

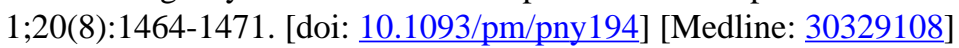

25. Queenan C, Cameron K, Snell A, Smalley J, Joglekar N. Patient heal thyself: reducing hospital readmissions with technology - enabled continuity of care and patient activation. Prod Oper Manag 2019 Aug 11;28(11):2841-2853. [doi: 10.1111/poms.13080]

26. Ammenwerth E, Hoerbst A, Lannig S, Mueller G, Siebert U, Schnell-Inderst P. Effects of adult patient portals on patient empowerment and health-related outcomes: a systematic review. Stud Health Technol Inform 2019 Aug 21;264:1106-1110. [doi: 10.3233/SHTI190397] [Medline: $\underline{31438096]}$

27. Schnock KO, Snyder JE, Fuller TE, Duckworth M, Grant M, Yoon C, et al. Acute care patient portal intervention: portal use and patient activation. J Med Internet Res 2019 Jul 18;21(7):e13336 [FREE Full text] [doi: 10.2196/13336] [Medline: $\underline{31322123}$ ]

28. Denneson L, Pisciotta M, Hooker E, Trevino A, Dobscha S. Impacts of a web-based educational program for veterans who read their mental health notes online. J Am Med Inform Assoc 2019 Jan 1;26(1):3-8. [doi: 10.1093/jamia/ocy134] [Medline: $\underline{30445648]}$

29. Ammenwerth E, Schnell-Inderst P, Hoerbst A. Patient empowerment by electronic health records: first results of a systematic review on the benefit of patient portals. Stud Health Technol Inform 2011;165:63-67. [Medline: 21685587]

30. Irizarry T, DeVito Dabbs A, Curran CR. Patient portals and patient engagement: a state of the science review. J Med Internet Res 2015 Jun 23;17(6):e148 [FREE Full text] [doi: 10.2196/jmir.4255] [Medline: 26104044]

31. Riippa I, Linna M, Rönkkö I. The effect of a patient portal with electronic messaging on patient activation among chronically ill patients: controlled before-and-after study. J Med Internet Res 2014 Nov 19;16(11):e257 [FREE Full text] [doi: 10.2196/jmir.3462] [Medline: 25413368]

32. Apter AJ, Bryant-Stephens T, Perez L, Morales KH, Howell JT, Mullen AN, et al. Patient portal usage and outcomes among adult patients with uncontrolled asthma. J Allergy Clin Immunol Pract 2020 Mar;8(3):965-70.e4. [doi: 10.1016/j.jaip.2019.09.034] [Medline: 31622684]

33. Otte-Trojel T, de Bont A, Rundall TG, van de Klundert J. How outcomes are achieved through patient portals: a realist review. J Am Med Inform Assoc 2014;21(4):751-757 [FREE Full text] [doi: 10.1136/amiajnl-2013-002501] [Medline: 24503882]

34. Wagner PJ, Dias J, Howard S, Kintziger KW, Hudson MF, Seol Y, et al. Personal health records and hypertension control: a randomized trial. J Am Med Inform Assoc 2012;19(4):626-634 [FREE Full text] [doi: 10.1136/amiajnl-2011-000349] [Medline: 22234404]

35. Schuit AS, Holtmaat K, Hooghiemstra N, Jansen F, Lissenberg-Witte BI, Coupé VM, et al. Efficacy and cost-utility of the ehealth application 'Oncokompas', supporting patients with incurable cancer in finding optimal palliative care, tailored to their quality of life and personal preferences: a study protocol of a randomized controlled trial. BMC Palliat Care 2019 Oct 23;18(1):85 [FREE Full text] [doi: 10.1186/s12904-019-0468-8] [Medline: 31647011] 
36. Dobson R, Whittaker R, Jiang Y, Maddison R, Shepherd M, McNamara C, et al. Effectiveness of text message based, diabetes self management support programme (SMS4BG): two arm, parallel randomised controlled trial. Br Med J 2018 May 17;361:k1959 [FREE Full text] [doi: 10.1136/bmj.k1959] [Medline: 29773539]

37. Almutairi N, Hosseinzadeh H, Gopaldasani V. The effectiveness of patient activation intervention on type 2 diabetes mellitus glycemic control and self-management behaviors: a systematic review of RCTs. Prim Care Diabetes 2020 Feb;14(1):12-20. [doi: 10.1016/j.pcd.2019.08.009] [Medline: 31543458]

38. Su D, Michaud TL, Estabrooks P, Schwab RJ, Eiland LA, Hansen G, et al. Diabetes management through remote patient monitoring: the importance of patient activation and engagement with the technology. Telemed J E Health 2019 Oct;25(10):952-959. [doi: 10.1089/tmj.2018.0205] [Medline: $\underline{30372366]}$

39. Kim JY, Wineinger NE, Steinhubl SR. The influence of wireless self-monitoring program on the relationship between patient activation and health behaviors, medication adherence, and blood pressure levels in hypertensive patients: a substudy of a randomized controlled trial. J Med Internet Res 2016 Jun 22;18(6):e116 [FREE Full text] [doi: 10.2196/jmir.5429] [Medline: 27334418]

40. Zimbudzi E, Lo C, Ranasinha S, Kerr PG, Polkinghorne KR, Teede H, et al. The association between patient activation and self-care practices: a cross-sectional study of an Australian population with comorbid diabetes and chronic kidney disease. Health Expect 2017 Dec;20(6):1375-1384 [FREE Full text] [doi: 10.1111/hex.12577] [Medline: 28675539]

41. McCabe PJ, Stuart-Mullen LG, McLeod CJ, O Byrne T, Schmidt MM, Branda ME, et al. Patient activation for self-management is associated with health status in patients with atrial fibrillation. Patient Prefer Adherence 2018;12:1907-1916 [FREE Full text] [doi: 10.2147/PPA.S172970] [Medline: 30288031]

42. Greene J, Hibbard JH. Why does patient activation matter? An examination of the relationships between patient activation and health-related outcomes. J Gen Intern Med 2012 May;27(5):520-526 [FREE Full text] [doi: 10.1007/s11606-011-1931-2] [Medline: 22127797]

43. Hibbard J, Stockard J, Mahoney E, Tusler M. Development of the patient activation measure (PAM): conceptualizing and measuring activation in patients and consumers. Health Serv Res 2004 Aug;39(4 Pt 1):1005-1026 [FREE Full text] [doi: 10.1111/j.1475-6773.2004.00269.x] [Medline: 15230939]

44. Georgsson M, Staggers N. Quantifying usability: an evaluation of a diabetes mhealth system on effectiveness, efficiency, and satisfaction metrics with associated user characteristics. J Am Med Inform Assoc 2016 Jan;23(1):5-11 [FREE Full text] [doi: 10.1093/jamia/ocv099] [Medline: 26377990]

45. Sauro J, Dumas J. Comparison of Three One-question, Post-task Usability Questionnaires. In: Proceedings of the SIGCHI Conference on Human Factors in Computing Systems. 2009 Presented at: CHI'09; April 4-9, 2009; Boston, MA. [doi: 10.1145/1518701.1518946]

46. Sauro J, Lewis J. Quantifying the User Experience: Practical Statistics for User Research. Waltham, MA: Morgan Kaufmann; 2012.

47. Kidd PS, Parshall MB. Getting the focus and the group: enhancing analytical rigor in focus group research. Qual Health Res 2000 May;10(3):293-308. [doi: 10.1177/104973200129118453] [Medline: 10947477]

48. Thorn S. Data analysis in qualitative research. Evid Based Nurs 2000;3:68-70. [doi: 10.1136/ebn.3.3.68]

49. Thomas DR. A general inductive approach for analyzing qualitative evaluation data. Am J Eval 2016 Jun 30;27(2):237-246. [doi: $10.1177 / 1098214005283748]$

50. Harvey L, Fowles JB, Xi M, Terry P. When activation changes, what else changes? the relationship between change in patient activation measure (PAM) and employees' health status and health behaviors. Patient Educ Couns 2012 Aug;88(2):338-343. [doi: 10.1016/j.pec.2012.02.005] [Medline: 22459636]

51. Mosen DM, Schmittdiel J, Hibbard J, Sobel D, Remmers C, Bellows J. Is patient activation associated with outcomes of care for adults with chronic conditions? J Ambul Care Manage 2007;30(1):21-29. [doi: 10.1097/00004479-200701000-00005] [Medline: $\underline{17170635]}$

52. Rask KJ, Ziemer DC, Kohler SA, Hawley JN, Arinde FJ, Barnes CS. Patient activation is associated with healthy behaviors and ease in managing diabetes in an indigent population. Diabetes Educ 2009;35(4):622-630. [doi: 10.1177/0145721709335004] [Medline: 19419972]

53. Rogvi S, Tapager I, Almdal T, Schiøtz ML, Willaing I. Patient factors and glycaemic control-associations and explanatory power. Diabet Med 2012 Oct;29(10):e382-e389. [doi: 10.1111/j.1464-5491.2012.03703.x] [Medline: 22540962]

54. Toobert DJ, Hampson SE, Glasgow RE. The summary of diabetes self-care activities measure: results from 7 studies and a revised scale. Diabetes Care 2000 Jul;23(7):943-950 [FREE Full text] [doi: 10.2337/diacare.23.7.943] [Medline: 10895844]

55. Gonzalez J, Safren S, Delahanty L, Cagliero E, Wexler D, Meigs J, et al. Symptoms of depression prospectively predict poorer self-care in patients with type 2 diabetes. Diabet Med 2008 Sep;25(9):1102-1107 [FREE Full text] [doi: 10.1111/j.1464-5491.2008.02535.x] [Medline: 19183315]

56. Watkins YJ, Quinn LT, Ruggiero L, Quinn MT, Choi Y. Spiritual and religious beliefs and practices and social support's relationship to diabetes self-care activities in African Americans. Diabetes Educ 2013;39(2):231-239 [FREE Full text] [doi: 10.1177/0145721713475843] [Medline: 23411653] 
57. Primožič S, Tavčar R, Avbelj M, Dernovšek MZ, Oblak MR. Specific cognitive abilities are associated with diabetes self-management behavior among patients with type 2 diabetes. Diabetes Res Clin Pract 2012 Jan;95(1):48-54. [doi: 10.1016/j.diabres.2011.09.004] [Medline: 21963107]

58. Cohen H, Shmukler C, Ullman R, Rivera C, Walker E. Measurements of medication adherence in diabetic patients with poorly controlled HbA(1c). Diabet Med 2010 Feb;27(2):210-216 [FREE Full text] [doi: 10.1111/j.1464-5491.2009.02898.x] [Medline: 20546266]

59. Bangor A, Kortum PT, Miller JT. An empirical evaluation of the system usability scale. Int J Hum-Comput Int 2008 Jul 30;24(6):574-594. [doi: 10.1080/10447310802205776]

60. Diggle P, Heagerty P, Liang K, Zeger S. Analysis of Longitudinal Data. Second Edition. Oxford, UK: Oxford University Press; 2002.

61. Wildenbos GA, Peute L, Jaspers M. Aging barriers influencing mobile health usability for older adults: a literature based framework (MOLD-US). Int J Med Inform 2018 Jun;114:66-75. [doi: 10.1016/j.ijmedinf.2018.03.012] [Medline: 29673606]

62. Bender MS, Cooper BA, Park LG, Padash S, Arai S. A feasible and efficacious mobile-phone based lifestyle intervention for Filipino Americans with type 2 diabetes: randomized controlled trial. JMIR Diabetes 2017 Dec 12;2(2):e30 [FREE Full text] [doi: $10.2196 /$ diabetes.8156] [Medline: $\underline{30291068}$ ]

63. Young H, Miyamoto S, Dharmar M, Tang-Feldman Y. Nurse coaching and mobile health compared with usual care to improve diabetes self-efficacy for persons with type 2 diabetes: randomized controlled trial. JMIR Mhealth Uhealth 2020 Mar 2;8(3):e16665 [FREE Full text] [doi: 10.2196/16665] [Medline: 32130184]

64. Block G, Azar KM, Romanelli RJ, Block TJ, Hopkins D, Carpenter HA, et al. Diabetes prevention and weight loss with a fully automated behavioral intervention by email, web, and mobile phone: a randomized controlled trial among persons with prediabetes. J Med Internet Res 2015 Oct 23;17(10):e240 [FREE Full text] [doi: 10.2196/jmir.4897] [Medline: 26499966]

65. Koot D, Goh PS, Lim RS, Tian Y, Yau TY, Tan NC, et al. A mobile lifestyle management program (GlycoLeap) for people with type 2 diabetes: single-arm feasibility study. JMIR Mhealth Uhealth 2019 May 24;7(5):e12965 [FREE Full text] [doi: 10.2196/12965] [Medline: 31127720]

66. Everett E, Kane B, Yoo A, Dobs A, Mathioudakis N. A novel approach for fully automated, personalized health coaching for adults with prediabetes: pilot clinical trial. J Med Internet Res 2018 Feb 27;20(2):e72 [FREE Full text] [doi: 10.2196/jmir.9723] [Medline: 29487046]

67. Bell AM, Fonda SJ, Walker MS, Schmidt V, Vigersky RA. Mobile phone-based video messages for diabetes self-care support. J Diabetes Sci Technol 2012 Mar 1;6(2):310-319 [FREE Full text] [doi: 10.1177/193229681200600214] [Medline: 22538140]

68. Spring B, Schneider K, McFadden HG, Vaughn J, Kozak AT, Smith M, et al. Multiple behavior changes in diet and activity: a randomized controlled trial using mobile technology. Arch Intern Med 2012 May 28;172(10):789-796 [FREE Full text] [doi: 10.1001/archinternmed.2012.1044] [Medline: 22636824]

69. Nelson LA, Mayberry LS, Wallston K, Kripalani S, Bergner EM, Osborn CY. Development and usability of REACH: a tailored theory-based text messaging intervention for disadvantaged adults with type 2 diabetes. JMIR Hum Factors 2016 Sep 8;3(2):e23 [FREE Full text] [doi: 10.2196/humanfactors.6029] [Medline: 27609738]

70. Gimbel RW, Pangaro L, Barbour G. America's 'undiscovered' laboratory for health services research. Med Care 2010 Aug;48(8):751-756. [doi: 10.1097/MLR.0b013e3181e35be8] [Medline: 20613659]

71. Saffari M, Ghanizadeh G, Koenig HG. Health education via mobile text messaging for glycemic control in adults with type 2 diabetes: a systematic review and meta-analysis. Prim Care Diabetes 2014 Dec;8(4):275-285. [doi: 10.1016/j.pcd.2014.03.004] [Medline: 24793589]

72. Sepah SC, Jiang L, Ellis RJ, McDermott K, Peters AL. Engagement and outcomes in a digital diabetes prevention program: 3-year update. BMJ Open Diabetes Res Care 2017;5(1):e000422 [FREE Full text] [doi: 10.1136/bmjdrc-2017-000422] [Medline: 28948027]

73. Zheng Y, Burke LE, Danford CA, Ewing LJ, Terry MA, Sereika SM. Patterns of self-weighing behavior and weight change in a weight loss trial. Int J Obes (Lond) 2016 Sep;40(9):1392-1396. [doi: 10.1038/ijo.2016.68] [Medline: 27113642]

\section{Abbreviations}

DoD: US Department of Defense

GEE: generalized estimating equations

$\mathbf{H b A}_{1 \mathbf{c}}$ : glycated hemoglobin

LDL: low-density lipoprotein

MHCE: Mobile Health Care Environment

mHealth: mobile health

PAM: Patient Activation Measure

PCMH: patient-centered medical home

PHI: personal health information 
PHR: personal health record

SDSCA: Summary of Diabetes Self-Care Activities

SUS: System Usability Scale

T2D: type 2 diabetes

Edited by G Eysenbach; submitted 24.01.20; peer-reviewed by S Jalil, N Lindström, B Eapen, H Hah, I Mircheva; comments to author 14.02.20; revised version received 21.03.20; accepted 12.04.20; published 26.05.20

Please cite as:

Gimbel RW, Rennert LM, Crawford P, Little JR, Truong K, Williams JE, Griffin SF, Shi L, Chen L, Zhang L, Moss JB, Marshall RC, Edwards KW, Crawford KJ, Hing M, Schmeltz A, Lumsden B, Ashby M, Haas E, Palazzo K

Enhancing Patient Activation and Self-Management Activities in Patients With Type 2 Diabetes Using the US Department of Defense

Mobile Health Care Environment: Feasibility Study

J Med Internet Res 2020;22(5):e17968

URL: http://www.jmir.org/2020/5/e17968/

doi: $\underline{10.2196 / 17968}$

PMID: 32329438

CRonald W Gimbel, Lior M Rennert, Paul Crawford, Jeanette R Little, Khoa Truong, Joel E Williams, Sarah F Griffin, Lu Shi, Liwei Chen, LingLing Zhang, Jennie B Moss, Robert C Marshall, Karen W Edwards, Kristy J Crawford, Marie Hing, Amanda Schmeltz, Brandon Lumsden, Morgan Ashby, Elizabeth Haas, Kelly Palazzo. Originally published in the Journal of Medical Internet Research (http://www.jmir.org), 26.05.2020. This is an open-access article distributed under the terms of the Creative Commons Attribution License (https://creativecommons.org/licenses/by/4.0/), which permits unrestricted use, distribution, and reproduction in any medium, provided the original work, first published in the Journal of Medical Internet Research, is properly cited. The complete bibliographic information, a link to the original publication on http://www.jmir.org/, as well as this copyright and license information must be included. 